\title{
ERRATA
}

Volume 53, Number 3 (2000), on the cover and in the article "Holocene Foraminifera as Indicators of Relative Estuarine-Lagoonal and Oceanic Influences in Estuarine Sediments of the River Murray, South Australia," by John H. Cann, Robert P. Bourman, and Elizabeth J. Barnett, pages 378-391 (doi:10.1006/qres.2000.2129): The following acknowledgment was inadvertently omitted: "The aerial photographs on the cover of Volume 53, No. 3, and Fig. 3 on page 381 were reproduced with permission of the South Australian Department of Environment, Heritage and Aboriginal Affairs, Resource Information Division, MAPLAND, 300 Richmond Road, Netley, South Australia 5037, Telephone $61+88226$ 4946."

This erratum is doi:10.1006/qres.2000.2184.

Volume 54, Number 2 (2000), in the article "Use of Rubidium to Date Loess and Paleosols of the Louchan Sequence, Central China," by Jun Chen, Junfeng Ji, Yang Chen, Zhisheng An, John A. Dearing, and Yongjin Wang, pages 198-205 (doi:10.1006/ qres.2000.2159): In the issue Table of Contents and on page 198, the word Louchan is misspelled in the title and should be changed to Luochuan. For the reader's convenience, the correct title is reproduced here.

\section{Use of Rubidium to Date Loess and Paleosols of the Luochuan Sequence, Central China}

This erratum is doi:10.1006/qres.2000.2185. 